九州大学学術情報リポジトリ

Kyushu University Institutional Repository

Effects of different sulfur ion concentration in nutrient solution and light source on glucosinolate contents in kale sprouts (Brassica oleracea var. acephala)

Park, Ye-Jin

Department of Bio-Environmental Chemistry, Chungnam National University

Jin-Chun, Hyuk

Department of Bio-Environmental Chemistry, Chungnam National University

Woo, Hyunnyung

Department of Bio-Environmental Chemistry, Chungnam National University

Maruyama, Akiko

Laboratory of Plant Nutrition, Department of Bioscience and Biotechnology, Faculty of Agriculture, Kyushu University

他

http://hdl. handle. net/2324/4377827

出版情報: Korean Journal of Agricultural Science (KJOAS). 44 (2), pp.261-271，2017-06.

Institute of Agricultural Science in College of Agriculture \& Life Sciences, Chungnam National University

バージョン :

権利関係: Creative Commons Attribution Non-Commercial International 


\title{
Effects of different sulfur ion concentration in nutrient solution and light source on glucosinolate contents in kale sprouts (Brassica oleracea var. acephala)
}

\author{
Ye-Jin Park' ${ }^{1}$ Jin-Hyuk Chun ${ }^{1}$, Hyunnyung Woo' ${ }^{1}$ Akiko Maruyama-Nakashita ${ }^{2}$, Sun-Ju Kim ${ }^{1 *}$ \\ 'Department of Bio-Environmental Chemistry, Chungnam National University, Daejeon 34134, Korea \\ ${ }^{2}$ Laboratory of Plant Nutrition, Faculty of Agriculture, Kyushu University, Fukuoka 812-8581, Japan \\ *Corresponding author: kimsunju@cnu.ac.kr
}

\begin{abstract}
The aim of this study was to investigate the amount of glucosinolates (GSLs) in kale sprouts (Brassica oleracea L. var. acephala) ('TBC') according to different concentrations of sulfur ions in sprout's nutrient solutions $(0.0,0.5,1.0$, and $2.0 \mathrm{mM})$ and to different light sources [Fluorescent lamp, Red, Blue, and Mix (R+B) LED]. Kale sprouts were cultivated in a growth chamber for 13 days in sulfur solutions. Kale sprouts were treated with fluorescent lamp and LED light sources for 5 days, from eight days after sowing to harvest. Amount of seven types of GSLs (progoitrin, sinigrin, 4-hydroxyglucobrassicin, glucobrassicin, 4-methoxyglucobrassicin, gluconasturtiin, and neoglucobrassicin) were measured in kale sprouts after harvest. The total GSL content was influenced by different sulfur solution concentration, and it was the highest at $\mathrm{S} 0.5 \mathrm{mM}\left(172.54 \mu \mathrm{mol} \cdot \mathrm{g}^{-1} \mathrm{DW}\right)$ and the lowest at S $2.0 \mathrm{mM}\left(163.09 \mu \mathrm{mol} \cdot \mathrm{g}^{-1} \mathrm{DW}\right)$. The GSL content was influenced by different light source, and it was the highest with Red LED $\left(159.23 \mu \mathrm{mol} \cdot \mathrm{g}^{-1} \mathrm{DW}\right)$ and the lowest with Blue LED $\left(147.57 \mu \mathrm{mol} \cdot \mathrm{g}^{-1} \mathrm{DW}\right)$. As the sulfur solution concentration increased under all light source, progoitrin and sinigrin contents tended to decrease while glucobrassicin content showed an upward tendency for all of the light sources. The content of glucobrassicin was higher than that of progitrin when treated with sulfur solutions for all LED light sources. Sinigrin, which has excellent anti-cancer effects, showed the highest rate (92.2\%) among all the GSLs, under all of the light sources.
\end{abstract}

Keywords: brassica vegetable, fluorescent lamp, HPLC analysis, light-emitting diode, sinigrin

Received: October 4, 2016

Revised: February 6, 2017

Accepted: February 20, 2017

Copyright: (C) 2017 Korean Journal of Agricultural Science.

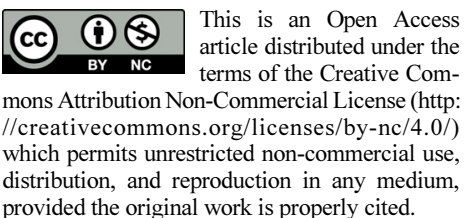

\section{Introduction}

케일(Brassica oleracea var. acephala)은 유럽 서북부가 원산지이며, 배추과(Brassicaceae)에 속하는 양배추(Brassica oleracea)에 가장 가까운 채소로서(Choi et al., 1995), 오랜 기간 동안 사 람과 가축 모두에게 식용으로 사용되고 있다(Rosa and Heaney, 1996). 케일은 비타민 C와 U, $\beta$ carotene, chlorophyll 및 칼슘, 인, 칼륨 등과 같은 무기질의 함량이 높아 영양학적으로 가치가 높다(Choi et al., 1995). 또한 혈당과 혈중 콜레스테롤을 저하시키며 유해물질 배설과 같은 효능 
이 있어 녹즙으로 주로 이용되고 있으며(Kang et al., 2005), 항암 물질로 알려진 글루코시놀레이트(Glucosinolates, GSLs)를 다량 함유하고 있다(Lee et al., 2012). GSLs와 같은 항암 물질 뿐만 아니라 항산화활성과 관련된 페놀 화 합물도 케일 내에 다량 존재한다(Jahangir et al., 2009).

GSLs는 배추과 식물들의 대표적인 2차 대사산물로서 겨자(B. juncea), 양배추(B. oleracea var. capitata), 무 (Raphanus sativus), 싹눈 양배추(B. oleracea var. gemmifera), 콜리플라워(B. oleracea var. botrytis), 브로콜리(B. oleracea var. italica), 케일 등에 많이 들어 있으며(Cartea et al., 2008), 질소와 황을 함유하고 있는 화합물이다. GSLs는 기본 구조에서 곁사슬 R기에 따라 분류가 되며(Fahey et al., 2001), 약 200종 이상 존재한다고 보고되어있 다(Clarke, 2010). GSL 생합성은 amino acid가 산소분자를 받고, aldoxime을 생성하면서 시작된다. Aldoxime 생성 후 cysteine에 함유되어 있는 -SH가 결합하여 thiohydroxamic acid가 된다. Thiohydroxamic acid의 S-glucosylation은 thiohydroximate glucosyltransferase (UDPG)에 의해 촉매되어 desulfo GSL 가 생성되고, 이를 3'-phosphoadenosine5'-phosphosulphate (PAPS)의 sulfate를 이용해 황산화 반응을 함으로써 GSLs를 합성한다(Halkier and Du, 1997; Fahey et al., 2001; Hayes et al., 2007).

황(sulfur)은 생체의 여러 가지 유기화합물의 구성성분이며, cysteine이나 methionine과 같은 함황 아미노산의 구 성성분으로 단백질에 함유되어 있다. 주로 화합물 내에서 SH 형태, S 형태로 존재하고 생체의 대사과정 중에 산화, 환원에 관여하여 radical에 의한 세포손상을 막을 수 있다(Kim et al., 2012). 황은 식물의 광합성과 호흡에 필요한 원 소이다. 식물이 생장하는데 소량을 필요로 하지만 필수 원소 중 하나로써 황이 결핍되면 식물체는 잎이 노랗게 변하 는 황백화 현상이 일어나고 질소 대사가 원활하지 못하여 생육이 저해된다(Hirai et al., 2003; Maruyama-Nakashita et al., 2003). 싹이 트는 과정동안 황을 공급해 주면, 배추과 새싹에 있는 GSL 합성이 증가할 수 있고, 새싹의 항암 활성이 증가한다(Kestwal et al., 2011). 또한 식물체 내에서 황 함량이 높을수록 GSL 축적이 많이 되며 황 함량의 $30 \%$ 까지 GSLs에 축적이 되고, 황이 결핍되면 생합성이 활성화 되지 못하여 GSL 함량이 감소한다고 보고되었다 (Falk et al., 2007). Kestwal et al. (2011)은 무 새싹채소 재배 시 황 $60 \mathrm{~kg} \cdot \mathrm{ha}^{-1}(1.01 \mathrm{mM})$ 를 보충하여 GSLs가 다섯 배 증가하고, 브로콜리 새싹채소 재배에서 황 무처리 $(0.48 \mathrm{mM})$ 보다 $60 \mathrm{~kg} \cdot \mathrm{ha}^{-1}$ 를 보충하였을 때, 2.5 배 증가한다 고 보고하였다.

Light-emitting diode (LED)는 형광등, 백열등 및 나트륨등과 같은 인공광원에 비해 수명이 길고 열 발생과 전력 소모량이 적다. 또한 다른 광원에 비해 식물체의 생장 및 광합성에 필요한 특정 파장을 혼합하거나 혼합비율을 임 의로 조절할 수 있어 작물 재배 연구에 많이 이용되고 있다(Bula et al., 1991; Heo et al., 2013). LED를 이용한 식물 재배는 식물의 생리학적 반응과 카로테노이드, GSLs 같은 이차대사산물의 생산에 중요한 영향을 미친다(Lefsrud et al., 2008). 적색(600 - $700 \mathrm{~nm}$ )은 광합성에서 엽록소가 흡수하는 파장인 $660 \mathrm{~nm}$ 에 가까워 식물 생장에 필수적이 며, 상추 재배 시 단일 적색 광에서 자란 상추는 단일 청색광에서 자란 상추보다 잎의 수가 많았고 줄기가 길었다 (Matsuda et al., 2004; Massa et al., 2008). 청색(400 - $500 \mathrm{~nm}$ )은 기공 개폐, $\mathrm{CO}_{2}$ 교환과 줄기신장 등의 식물 생장에 중요한 역할을 한다(Schwartz and Zeiger, 1984). 밀 재배 시 적색광에 청색광을 혼합하면 잎에서 기공전도도와 광 합성 효율이 증가한다고 보고되었고(Goins et al., 1997), 벼를 재배할 때도 단일 적색광보다 적색광과 청색광을 혼 합하면 더 높은 광합성 효율이 나타난다고 보고되었다(Matsuda et al., 2004; Massa et al., 2008). Carvalho and Folta (2014)에서 케일 새싹채소 재배 시 총 GSL 함량은 근적외선(730 nm)에서 가장 높게 나타났고(3.65 $\left.\mu \mathrm{mol} \cdot \mathrm{g}^{-1} \mathrm{DW}\right)$, 다른 광원 처리구 $(470,660 \mathrm{~nm})$ 와 암조건을 비교 $\left(2.57\right.$ - $\left.3.12 \mu \mathrm{mol} \cdot \mathrm{g}^{-1} \mathrm{DW}\right)$ 하면 약 15 - $42 \%$ 더 높게 나타났다고 보 고하였다. 이러한 결과는 청색광이 잎의 광합성 효율과 건물 생산에서 영향을 미치는 것으로 사료된다(Yorio et al., 2001; Matsuda et al., 2004).

최근 시설재배를 통해 작물 생산뿐만 아니라 기능성 성분을 증대하고자 하는 다양한 연구가 진행되고 있다. 본 실험에서는 작물의 재배환경 요인 중 특정파장에 따라 식물의 생장과 이차대사산물 합성에 영향을 주는 광원[형 
광등, 적색 $\mathrm{LED}$, 청색 $\mathrm{LED}$, 적+청 $(7: 3)$ 혼합색 $\mathrm{LED}]$ 과 $\mathrm{GSLs}$ 의 구성성분인 황 양액 농도 $(0.0,0.5,1.0,2.0 \mathrm{mM})$ 를 조절하여 케일 새싹채소 내 GSL 함량을 조사하였다.

\section{Materials and Methods}

\section{시약}

Acetonitrile $\left(\mathrm{CH}_{3} \mathrm{CN}\right)$ 과 methanol $\left(\mathrm{CH}_{3} \mathrm{OH}\right)$ 은 J.T. Baker Chemical Co. (New Jersey, USA)제품을 사용하였다. DEAE-Sephadex A-25는 GE Healthcare Bio-Sciences AB (Uppsala, Sweden)제품을 사용했고, Sodium acetate $\left(\mathrm{NaC}_{2} \mathrm{H}_{3} \mathrm{O}_{2} \cdot 3 \mathrm{H}_{2} \mathrm{O}\right)$ 은 Samchun Pure Chemical Co., Ltd. (Pyeongtaek, Korea)제품을 사용하였다. Sinigrin (2-propenyl GSL), aryl sulfatase (type H-1, EC 3.1.6.1)는 Sigma-Aldrich Chemical Co. (St Louis, MO, USA)제품을 사용하였다.

\section{케일 새싹 재배}

케일 종자(케일 ‘TBC', 아시아종묘 Korea) $2 \mathrm{~g}$ (282개)을 칭량하여 초순수에 6시간 침종시켰다. 포트 $(7 \times 7 \times 12 \mathrm{~cm})$ 에 순수를 흡수시킨 스펀지를 깐 다음 침종시킨 종자를 고르게 파종하였다. 포트를 식물생장기(growth chamber)에 넣 고 2014년 3월 6일부터 19일까지 13일간 재배하였다. 재배기간 중 파종 후 8일간 암조건 하에서 재배하였다. 형광등과 $\mathrm{LED}$ 광원[적색 LED $(640 \mathrm{~nm})$, 청색 LED $(430 \mathrm{~nm})$, 적+청 혼합색 LED]은 파종 8 일 후 수확 전까지 총 5 일간 처리하였 고, 적+청 혼합색 $\mathrm{LED}$ 의 혼합 비율은 적 : 청 $=7: 3$ 이었다. 식물생장기 내부 환경은 형광등에서 온도 $25^{\circ} \mathrm{C}$, 습도 $45 \%$, 광량 $33 \mu \mathrm{mol} \cdot \mathrm{m}^{-2} \cdot \mathrm{s}^{-1}$ 로 유지하였고, $\mathrm{LED}$ 에서 온도 $25^{\circ} \mathrm{C}$, 습도 $70 \%$, 광량 $200 \mu \mathrm{mol} \cdot \mathrm{m}^{-2} \cdot \mathrm{s}^{-1}$ 로 유지하였다. 파종 후 각각 다른 황 양액 농도 $\left(0.0,0.5,1.0,2.0 \mathrm{mM}\right.$ )를 $60 \mathrm{~mL}$ 씩 처리하였으며, 황 양액은 $\mathrm{MgSO}_{4} \cdot 7 \mathrm{H}_{2} \mathrm{O}$ (Samchun Pure Chemical Co., Ltd.)를 이용하여 만들었다. 동일한 황 양액 농도를 유지하기 위해 매일 같은 시간에 양액을 갈아주었고, 광량을 동일하게 조성하기 위해 식물생장기 안의 포트를 하루에 한번 시계방향으로 이동시켜 주었다.

\section{Glucosinolate 추출}

시료는 뿌리를 제외한 가식부 전체를 3 반복으로 수확 후 동결 건조하여 분말화한 후, $100 \mathrm{mg}$ 을 칭량하여 2.0 $\mathrm{mL}$-Eppendorf tube에 넣고 끓는 $70 \%$ methanol $\left(70^{\circ} \mathrm{C}\right)$ 을 $1.5 \mathrm{~mL}$ 넣어 진동혼합(vortex) 하였다. 항온수조 $\left(70^{\circ} \mathrm{C}\right)$ 에 서 5 분간 조(crude) GSLs를 추출하고, 원심분리 $\left(12,000 \mathrm{rpm}, 10 \mathrm{~min}, 4^{\circ} \mathrm{C}\right)$ 한 후에 상층액은 시험관에 수거하고, 동 일한 과정으로 총 3 회 추출하여 각 상층액을 합하였다.

미니 컬럼 충진용 DEAE Sephadex A-25는 초순수에 녹여 분액여두에 넣은 다음 초순수가 거의 빠져나가면 0.5 $\mathrm{M}$ sodium acetate을 넣어 $\mathrm{H}^{+}$형태로 활성화 시켰다. 탈지면으로 막은 mini-column에 활성화된 DEAE Sephadex $\mathrm{A}-25$ 에 $1,000 \mu \mathrm{L}$ pipet tip을 넣은 다음 GSL 조추출물을 pasteur pipet으로 로딩 하였다. 로딩 시킨 조추출물이 다 빠 지면 초순수 $2 \mathrm{~mL}$ 를 로딩 하여 컬럼에 남아있는 불순물을 제거하였다. 초순수가 다 빠져나가면 paraffin film으로 컬럼 아래 부분을 막고 aryl sulfatase solution $75 \mu \mathrm{L}$ 을 넣은 후 컬럼 위 부분을 paraffin film으로 막고 16시간 동안 상온에서 정치하였다. 용출을 위해 16 시간 후에 $2.0 \mathrm{~mL}$-Eppendorf tube에 초순수 $(0.5 \mathrm{~mL} \times 3$ 회 $)$ 로 DS-GSLs (desulfo-GSLs)를 용출시켰다. 용출시킨 시료(DS-GSLs)는 $0.45 \mu \mathrm{m}$ hydrophilic PTFE syringe filter (직경 $13 \mathrm{~mm}$ ) 로 여과한 후, HPLC용 vial병에 넣어 냉장 보관하였다.

\section{$\mathrm{HPLC}$ 분석}

DS-GSLs의 분석은 1200 series HPLC system (Agilent Technologies, CA, USA)를 사용하였다. 분석 컬럼은 Inertsil ODS-3 column $(150 \times 3.0 \mathrm{~mm}$ I.d., particle size $3 \mu \mathrm{m})$, 가드 컬럼은 Inertsil ODS-2 Cartridge Guard column E 
$(10 \times 2.0 \mathrm{~mm}$ I.d., particle size $5 \mu \mathrm{m})(\mathrm{GL}$ Science, Tokyo, Japan)를 사용하였다. 검출 파장은 $227 \mathrm{~nm}$, 컬럼 온도는 $40^{\circ} \mathrm{C}$, 유량은 $0.4 \mathrm{~mL} \cdot \mathrm{min}^{-1}$ 로 설정하였다. 시료는 automatic injector를 사용하여 $10.0 \mu \mathrm{L}$ 주입하였다. 이동상 용액 은 용매 A (초순수)와 용매 B (acetonitrile)를 사용하였다. 용매 B를 2분까지는 $0 \%$ 로 유지시키고 7 분까지 $0 \%$ 에서 $10 \%, 16$ 분까지 $10 \%$ 에서 $31 \%$ 로 증가시키고 19 분까지는 $31 \%$ 를 유지시키다가 21 분까지 $31 \%$ 에서 $0 \%$ 로 감소시킨 후 27 분까지는 $0 \%$ 로 유지시켰다. 각 GSL 성분은 4000 QTrap LC-ESI-MS/MS system (Applied Biosystems Instrument) 를 사용하여, positive ion mode $\left([\mathrm{M}+\mathrm{H}]^{+}\right)$로 동정하였고, 외부표준물질인 sinigrin의 HPLC 피크 면적과 각 성분의 면적을 비교하여 정량화 $\left(\mu \mathrm{mol} \cdot \mathrm{g}^{-1} \mathrm{DW}\right)$ 하였다.

\section{통계 분석}

HPLC 분석 결과는 Microsoft Office Excel 2010을 이용하여 각 성분에 대한 함량의 평균값과 반복 $(n=3)$ 의 표준 편차(SD, standard deviation)를 구하였다. 유의수준 $(p)$ 은 0.05 이하로 설정하였고, 사후분석은 Tukey 검정법으로 결정하였다. 통계처리 프로그램은 IBM SPSS ${ }^{\circledR} 21$ Statistics을 사용하였다.

\section{Results and Discussion}

\section{케일 새싹의 생장}

케일 새싹의 길이는 청색 $\operatorname{LED}(5.05 \mathrm{~cm})$ 를 제외한 나머지 광원에서 평균 $5.43 \mathrm{~cm}$ 로 큰 차이를 보이지 않았으며,

Table 1. Plant growth parameter $(n=3)$ of kale sprouts grown with different concentrations of sulfur solutions and different light sources.

\begin{tabular}{|c|c|c|c|c|c|}
\hline \multicolumn{2}{|c|}{ Treatments } & \multirow{2}{*}{$\begin{array}{l}\text { Height } \\
(\mathrm{cm})\end{array}$} & \multirow{2}{*}{$\begin{array}{c}\text { Fresh weight } \\
(\mathrm{g})\end{array}$} & \multirow{2}{*}{$\begin{array}{c}\text { Dry weight } \\
\text { (g) }\end{array}$} & \multirow{2}{*}{$\begin{array}{c}\text { Water content } \\
(\%)\end{array}$} \\
\hline Light sources & Sulfur (mM) & & & & \\
\hline \multirow[t]{4}{*}{ Fluorescent } & 0.0 & $5.41 \pm 0.13 \mathrm{a}^{\mathrm{z}}$ & $9.31 \pm 0.48 \mathrm{a}$ & $0.76 \pm 0.02 \mathrm{a}$ & $91.8 \pm 0.17 \mathrm{a}$ \\
\hline & 0.5 & $5.19 \pm 0.45 \mathrm{a}$ & $8.39 \pm 0.85 a$ & $0.63 \pm 0.16 \mathrm{a}$ & $92.5 \pm 1.62 \mathrm{a}$ \\
\hline & 1.0 & $5.63 \pm 0.28 \mathrm{a}$ & $8.42 \pm 0.83 a$ & $0.67 \pm 0.13 \mathrm{a}$ & $92.0 \pm 0.82 \mathrm{a}$ \\
\hline & 2.0 & $5.37 \pm 0.18 \mathrm{a}$ & $9.32 \pm 0.51 \mathrm{a}$ & $0.78 \pm 0.03 a$ & $91.6 \pm 0.45 \mathrm{a}$ \\
\hline \multicolumn{2}{|c|}{ Ave. } & $5.40 \pm 0.18$ & $8.86 \pm 0.76$ & $0.71 \pm 0.11$ & $92.0 \pm 0.87^{\mathrm{y}}$ \\
\hline \multirow[t]{4}{*}{ Red LED } & 0.0 & $5.33 \pm 0.21 \mathrm{a}$ & $9.39 \pm 0.10 \mathrm{a}$ & $0.86 \pm 0.02 \mathrm{a}$ & $90.9 \pm 0.28 \mathrm{a}$ \\
\hline & 0.5 & $5.52 \pm 0.24 \mathrm{a}$ & $8.68 \pm 1.26 \mathrm{a}$ & $0.81 \pm 0.10 \mathrm{a}$ & $90.7 \pm 0.45 \mathrm{a}$ \\
\hline & 1.0 & $5.47 \pm 0.18 \mathrm{a}$ & $9.14 \pm 0.98 \mathrm{a}$ & $0.88 \pm 0.12 \mathrm{a}$ & $90.4 \pm 0.54 a$ \\
\hline & 2.0 & $5.59 \pm 0.32 \mathrm{a}$ & $9.76 \pm 1.28 \mathrm{a}$ & $0.94 \pm 0.11 \mathrm{a}$ & $90.3 \pm 0.17 \mathrm{a}$ \\
\hline \multicolumn{2}{|c|}{ Ave. } & $5.48 \pm 0.11$ & $9.24 \pm 0.97$ & $0.87 \pm 0.10$ & $90.6 \pm 0.40$ \\
\hline \multirow[t]{4}{*}{ Blue LED } & 0.0 & $5.06 \pm 0.42 \mathrm{a}$ & $8.63 \pm 0.11 \mathrm{a}$ & $0.71 \pm 0.01 b$ & $91.7 \pm 0.20 \mathrm{a}$ \\
\hline & 0.5 & $5.00 \pm 0.56 \mathrm{a}$ & $9.16 \pm 0.42 \mathrm{a}$ & $0.79 \pm 0.02 \mathrm{a}$ & $91.4 \pm 0.26 \mathrm{a}$ \\
\hline & 1.0 & $5.14 \pm 0.58 \mathrm{a}$ & $8.32 \pm 0.78 a$ & $0.75 \pm 0.02 \mathrm{ab}$ & $91.0 \pm 0.79 a$ \\
\hline & 2.0 & $5.00 \pm 0.25 \mathrm{a}$ & $8.94 \pm 0.14 \mathrm{a}$ & $0.77 \pm 0.04 \mathrm{ab}$ & $91.4 \pm 0.58 \mathrm{a}$ \\
\hline \multicolumn{2}{|c|}{ Ave. } & $5.05 \pm 0.07$ & $8.76 \pm 0.51$ & $0.76 \pm 0.04$ & $91.4 \pm 0.52$ \\
\hline \multirow[t]{4}{*}{$\operatorname{Mix}(\mathrm{R}+\mathrm{B}) \mathrm{LED}$} & 0.0 & $5.51 \pm 0.36 \mathrm{a}$ & $8.92 \pm 0.84 a$ & $0.93 \pm 0.05 a$ & $89.5 \pm 0.51 \mathrm{a}$ \\
\hline & 0.5 & $5.37 \pm 0.15 \mathrm{a}$ & $7.77 \pm 0.64 \mathrm{a}$ & $0.80 \pm 0.04 \mathrm{~b}$ & $89.7 \pm 0.41 \mathrm{a}$ \\
\hline & 1.0 & $5.29 \pm 0.42 \mathrm{a}$ & $9.00 \pm 0.52 \mathrm{a}$ & $0.91 \pm 0.03 \mathrm{a}$ & $89.9 \pm 0.52 a$ \\
\hline & 2.0 & $5.48 \pm 0.40 \mathrm{a}$ & $8.84 \pm 0.11 \mathrm{a}$ & $0.95 \pm 0.03 a$ & $89.2 \pm 0.19 a$ \\
\hline \multicolumn{2}{|c|}{ Ave. } & $5.41 \pm 0.10$ & $8.63 \pm 0.73$ & $0.90 \pm 0.07$ & $89.6 \pm 0.45$ \\
\hline
\end{tabular}

${ }^{\mathrm{y}}$ Average water contents $(\%)$ based on the $\mathrm{S}$ concentrations $(n=12)$.

${ }^{\mathrm{z}}$ Within each column, values followed by the same letters are not significantly different at $\mathrm{p} \leq 0.05$, using Tukey's multiple-range test $(n=3)$. 
생체중은 형광등에서 황 2.0 (9.32), 적색 $\mathrm{LED}$ 에서 황 2.0 (9.76), 청색 $\mathrm{LED}$ 에서 황 0.5 (9.16), 적+청 혼합색(7 : 3) $\mathrm{LED}$ 에서 황 $1.0 \mathrm{mM}(9.00 \mathrm{~g})$ 이 높았다. 황 양액 농도와 광원에 따른 케일 새싹의 길이, 생체중 변화는 큰 차이를 보 이지 않았다. 수분함량은 형광등(92.0) > 청색 LED (91.4) > 적색 LED (90.6) > 적+청 혼합색 LED (89.6\%) 순으로 높았고, 황 양액 농도에 따른 변화는 평균 $90.9 \%$ 로 크게 차이 나지 않았다. 식물의 생장은 황양액의 농도, 광원의 종류에 의해 유의차이를 나타내지 않았다(Table 1).

\section{GSL 분리 및 동정}

케일 새싹채소 내 GSLs를 HPLC 및 LC-MS/MS로 분석한 결과, 7종류의 GSLs (progoitrin, sinigrin, 4-hydroxyglucobrassicin, glucobrassicin, 4-methoxy- glucobrassicin, gluconasturtiin, neoglucobrassicin)를 분리 및 동정하였다(Table 2, Fig. 1).

Table 2. Glucosinolates identified in kale sprouts grown with different concentrations of sulfur solutions and different light sources.

\begin{tabular}{crlcc}
\hline No. $^{\mathrm{w}}$ & RT $^{\mathrm{x}}$ & \multicolumn{1}{c}{ Trivial (semi-systematic) names } & $\begin{array}{c}\text { [M+H] } \\
(\mathrm{m} / \mathbf{z})^{\mathrm{y}}\end{array}$ & $\begin{array}{c}\text { Response } \\
\text { factor }^{\mathrm{z}}\end{array}$ \\
\hline 1 & 9.36 & Progoitrin (4-methylsulfinybutyl GSL) & 310 & 1.09 \\
2 & 10.20 & Sinigrin (2-propenyl GSL) & 280 & 1.00 \\
3 & 13.65 & 4-Hydroxyglucobrassicin (4-hydroxy-3-indolylmethyl GSL) & 385 & 0.28 \\
4 & 16.30 & Glucobrassicin (3-indolymethyl GSL) & 369 & 0.29 \\
5 & 17.26 & 4-Methoxyglucobrassicin (4-methoxy-3-indolylmethyl GSL) & 399 & 0.25 \\
6 & 17.64 & Gluconasturtiin (2-phenylethyl GSL) & 344 & 0.95 \\
7 & 19.46 & Neoglucobrassicin (1-methoxy-3-indolymethyl GSL) & 399 & 0.20 \\
\hline
\end{tabular}

wo., the elution order of HPLC analysis (Fig. 1).

${ }^{\mathrm{x}} \mathrm{RT}$, retention time ( $\left.\mathrm{min}\right)$.

${ }^{\mathrm{y}}$ As a desulfo-glucosinolate.

${ }^{\mathrm{z}}$ The international organization for standardization (ISO 9167-1, 1992).

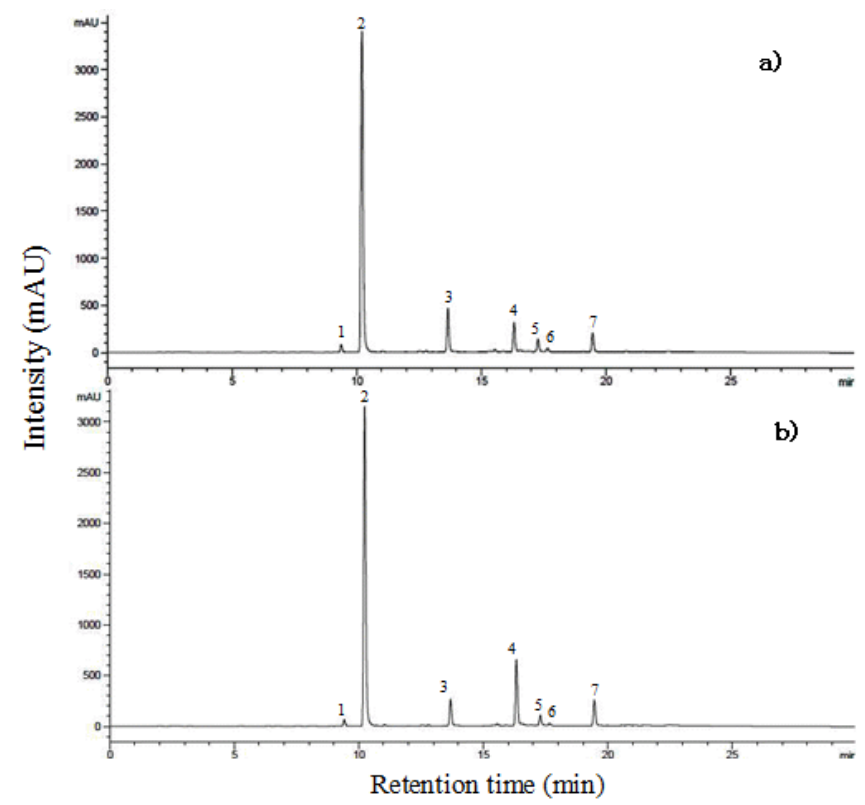

Fig. 1. HPLC chromatograms of glucosinolates separated from kale sprouts treated with (a) S $2.0 \mathrm{mM}+$ Fluorescent lamp and (b) S 2.0 mM + Red LED + Blue LED Mix. Peak numbers refer to the GSLs listed in Table 2. 
Table 3. Glucosinolate contents ( $\mu \mathrm{mol} / \mathrm{g} \mathrm{DW}$ ) in kale sprouts $(n=3)$ treated with different concentrations of sulfur solutions and different light sources (Fluorescent and Red LED).

\begin{tabular}{|c|c|c|c|c|c|c|c|c|c|c|}
\hline \multirow{2}{*}{ No. ${ }^{z}$} & \multirow{2}{*}{ Trivial name } & \multicolumn{5}{|c|}{ Fluorescent } & \multicolumn{4}{|c|}{ Red LED } \\
\hline & & $\mathrm{S}(\mathrm{mM})$ & 0.0 & 0.5 & 1.0 & 2.0 & 0.0 & 0.5 & 1.0 & 2.0 \\
\hline 1 & Progoitrin & & $3.29 \pm 0.49 \mathrm{a}$ & $3.24 \pm 0.03 \mathrm{a}$ & $2.70 \pm 0.94 \mathrm{a}$ & $3.09 \pm 0.40 \mathrm{a}$ & $3.80 \pm 0.59 \mathrm{a}$ & $3.34 \pm 0.61 \mathrm{a}$ & $3.02 \pm 0.66 \mathrm{a}$ & $3.20 \pm 0.59 \mathrm{a}$ \\
\hline 2 & Sinigrin & & $142.94 \pm 3.23 a$ & $147.10 \pm 7.44 a$ & $135.21 \pm 20.16 a$ & $146.71 \pm 9.63 \mathrm{a}$ & \multicolumn{2}{|c|}{$141.07 \pm 23.79 \mathrm{a} 146.10 \pm 5.15 \mathrm{a}$} & \multicolumn{2}{|c|}{$137.97 \pm 10.37 \mathrm{a} 135.25 \pm 6.56 \mathrm{a}$} \\
\hline 3 & 4-Hydroxyglucobrassicin & & $4.59 \pm 0.52 \mathrm{a}$ & $5.20 \pm 0.21 \mathrm{a}$ & $4.62 \pm 0.28 \mathrm{a}$ & $4.88 \pm 0.44 a$ & $3.26 \pm 1.12 \mathrm{a}$ & $4.56 \pm 0.79 \mathrm{a}$ & $4.52 \pm 1.04 a$ & $5.14 \pm 0.65 \mathrm{a}$ \\
\hline 4 & Glucobrassicin & & $1.76 \pm 0.20 \mathrm{c}$ & $2.52 \pm 0.13 b$ & $2.80 \pm 0.44 a b$ & $3.35 \pm 0.24 a$ & $2.78 \pm 0.57 \mathrm{~b}$ & $4.85 \pm 0.95 b$ & $5.55 \pm 1.35 b$ & $8.55 \pm 1.34 \mathrm{a}$ \\
\hline 5 & 4-Methoxyglucobrassicin & & $1.63 \pm 0.11 \mathrm{a}$ & $1.59 \pm 0.17 \mathrm{a}$ & $1.43 \pm 0.06 \mathrm{a}$ & $1.63 \pm 0.05 \mathrm{a}$ & $1.34 \pm 0.38 \mathrm{a}$ & $1.50 \pm 0.22 \mathrm{a}$ & $1.22 \pm 0.19 \mathrm{a}$ & $1.69 \pm 0.32 \mathrm{a}$ \\
\hline 6 & Gluconasturtiin & & $1.53 \pm 0.71 \mathrm{a}$ & $1.84 \pm 0.45 \mathrm{a}$ & $1.93 \pm 0.46 \mathrm{a}$ & $2.04 \pm 0.18 \mathrm{a}$ & $2.47 \pm 0.37 \mathrm{a}$ & $2.38 \pm 0.36 \mathrm{a}$ & $2.04 \pm 0.19 \mathrm{a}$ & $1.98 \pm 0.11 \mathrm{a}$ \\
\hline \multirow[t]{2}{*}{7} & Neoglucobrassicin & & $0.48 \pm 0.15 \mathrm{a}$ & $0.74 \pm 0.27 \mathrm{a}$ & $0.96 \pm 0.38 \mathrm{a}$ & $1.28 \pm 0.47 \mathrm{a}$ & $1.66 \pm 0.24 a$ & $2.08 \pm 0.57 \mathrm{a}$ & $2.28 \pm 1.20 \mathrm{a}$ & $3.31 \pm 0.54 \mathrm{a}$ \\
\hline & Total & & $156.21 \pm 4.47 \mathrm{a}$ & $162.23 \pm 6.89 \mathrm{a}$ & $149.65 \pm 22.41 \mathrm{a}$ & $162.96 \pm 9.99 \mathrm{a}$ & \multicolumn{2}{|c|}{$156.38 \pm 26.51 \mathrm{a} 164.81 \pm 6.34 \mathrm{a}$} & $156.61 \pm 14.57 \mathrm{a}$ & $159.11 \pm 5.53 \mathrm{a}$ \\
\hline
\end{tabular}

${ }^{\mathrm{z}}$ No., the elution order of HPLC analysis (Fig. 1).

Within each column, values followed by the same letters are not significantly different at $\mathrm{p} \leq 0.05$, using Tukey's multiple-range test $(n=3)$.

Table 4. Glucosinolate contents ( $\mu \mathrm{mol} / \mathrm{g} \mathrm{DW})$ in kale sprouts $(n=3)$ treated with different concentrations of sulfur solutions and different light sources (Blue LED and Mix LED).

\begin{tabular}{|c|c|c|c|c|c|c|c|c|c|c|}
\hline \multirow{2}{*}{ No. ${ }^{z}$} & \multirow{2}{*}{ Trivial name } & \multirow[b]{2}{*}{$\mathrm{S}(\mathrm{mM})$} & \multicolumn{4}{|c|}{ Blue LED } & \multicolumn{4}{|c|}{$\operatorname{Mix}(\mathrm{R}+\mathrm{B}) \mathrm{LED}$} \\
\hline & & & 0.0 & 0.5 & 1.0 & 2.0 & 0.0 & 0.5 & 1.0 & 2.0 \\
\hline 1 & Progoitrin & & $2.89 \pm 0.27 \mathrm{a}$ & $2.24 \pm 0.37 \mathrm{ab}$ & $2.01 \pm 0.10 \mathrm{~b}$ & $1.90 \pm 0.39 b$ & $4.21 \pm 0.23 \mathrm{a}$ & $3.60 \pm 0.16 \mathrm{ab}$ & $3.31 \pm 0.76 \mathrm{ab}$ & $2.67 \pm 0.62 \mathrm{~b}$ \\
\hline 2 & Sinigrin & & $143.10 \pm 6.66 \mathrm{a}$ & $137.75 \pm 5.83 \mathrm{a}$ & $135.26 \pm 8.19 \mathrm{a}$ & $125.98 \pm 15.47 \mathrm{a}$ & $143.06 \pm 13.01 \mathrm{a} 1$ & $147.24 \pm 8.62 \mathrm{a}$ & $139.67 \pm 10.76 \mathrm{a}$ & $126.98 \pm 15.78 \mathrm{a}$ \\
\hline 3 & 4-Hydroxyglucobrassicin & & $4.21 \pm 0.91 \mathrm{a}$ & $4.31 \pm 0.57 \mathrm{a}$ & $4.12 \pm 0.82 \mathrm{a}$ & $3.65 \pm 0.68 \mathrm{a}$ & $4.13 \pm 0.20 \mathrm{a}$ & $3.93 \pm 0.52 \mathrm{a}$ & $3.79 \pm 0.45 \mathrm{a}$ & $3.42 \pm 0.39 \mathrm{a}$ \\
\hline 4 & Glucobrassicin & & $1.35 \pm 0.16 \mathrm{~b}$ & $2.37 \pm 0.46 \mathrm{ab}$ & $2.24 \pm 0.48 b$ & $3.80 \pm 0.95 \mathrm{a}$ & $3.67 \pm 0.73 b$ & $6.61 \pm 1.13 \mathrm{ab}$ & $5.92 \pm 0.50 \mathrm{ab}$ & $8.76 \pm 2.88 \mathrm{a}$ \\
\hline 5 & 4-Methoxyglucobrassicin & & $1.02 \pm 0.24 \mathrm{a}$ & $1.32 \pm 0.27 \mathrm{a}$ & $1.17 \pm 0.13 \mathrm{a}$ & $1.34 \pm 0.10 \mathrm{a}$ & $1.79 \pm 0.35 \mathrm{a}$ & $1.54 \pm 0.55 \mathrm{a}$ & $1.35 \pm 0.12 \mathrm{a}$ & $1.43 \pm 0.11 \mathrm{a}$ \\
\hline 6 & Gluconasturtiin & & $1.27 \pm 0.34 \mathrm{a}$ & $1.72 \pm 0.35 \mathrm{a}$ & $1.46 \pm 0.11 \mathrm{a}$ & $1.60 \pm 0.08 \mathrm{a}$ & $1.78 \pm 0.19 \mathrm{a}$ & $1.52 \pm 0.41 \mathrm{a}$ & $1.70 \pm 0.13 \mathrm{a}$ & $1.56 \pm 0.16 \mathrm{a}$ \\
\hline \multirow[t]{2}{*}{7} & Neoglucobrassicin & & $0.30 \pm 0.09 \mathrm{a}$ & $0.67 \pm 0.44 \mathrm{a}$ & $0.39 \pm 0.07 \mathrm{a}$ & $0.82 \pm 0.12 \mathrm{a}$ & $2.34 \pm 0.25 \mathrm{a}$ & $2.00 \pm 0.27 \mathrm{a}$ & $2.26 \pm 0.43 \mathrm{a}$ & $2.47 \pm 0.64 a$ \\
\hline & Total & & $154.14 \pm 5.84 a$ & $150.39 \pm 7.29 \mathrm{a}$ & $146.65 \pm 9.77 \mathrm{a}$ & $139.09 \pm 16.91 \mathrm{a}$ & $160.99 \pm 12.93 \mathrm{a} 1$ & $166.44 \pm 8.45 \mathrm{a}$ & $158.00 \pm 12.64 \mathrm{a}$ & $147.30 \pm 20.37 \mathrm{a}$ \\
\hline
\end{tabular}

${ }^{\mathrm{z}}$ No., the elution order of HPLC analysis (Fig. 1).

Within each column, values followed by the same letters are not significantly different at $\mathrm{p} \leq 0.05$, using Tukey's multiple-range test $(n=3)$.

\section{황 양액 농도에 따른 GSL 함량}

Kestwal et al. (2011)은 브로콜리의 새싹채소 재배에서 황 무처리구(0.48)보다 $60 \mathrm{~kg} \cdot \mathrm{ha}^{-1}$ 을 보충하였을 때 $(1.01 \mathrm{mM}) \mathrm{GSLs}$ 가 2.5배 증가하고, 무 새싹채소 재배 시 황 $60 \mathrm{~kg} \cdot \mathrm{ha}^{-1}$ 를 보충하였을 때 GSLs가 다섯 배 증가한다 고 보고하였고, Falk et al. (2007)은 케일 재배 시 S 농도가 증가 $(0.125 \rightarrow 2.0 \mathrm{mM})$ 할수록 총 GSL 함량이 6.73배 증 가 $\left(0.59 \rightarrow 3.97 \mu \mathrm{mol} \cdot \mathrm{g}^{-1} \mathrm{DW}\right)$ 한다고 보고하였다. 본 연구에서는 황 양액 농도가 0.5 에서 $2.0 \mathrm{mM}$ 로 증가하였을 때, 총 GSL 함량이 1.06 배로 증가량이 미미하였다. 그렇지만, 상기 연구의 결과는 식물 성체, 본 연구는 새싹채소로 수행한 연구이므로 직접적인 비교가 어려운 것으로 사료된다. 각 GSL 성분별 함량 범위는 progoitrin (2.72 - 3.55), sinigrin (133.73 - 144.55), 4-hydroxyglucobrassicin (4.05 - 4.50), glucobrassicin (2.39 - 6.11), 4-methoxyglucobrassicin (1.29 - 1.52), gluconasturtiin (1.76 - 1.87), neoglucobrassicin (1.19 - $\left.1.97 \mu \mathrm{mol} \cdot \mathrm{g}^{-1} \mathrm{DW}\right)$ 으로 나타났다 (Table 5). 모 든 광원에서 황 양액 농도가 증가할수록 progoitrin과 sinigrin 함량은 감소하였고, 대조적으로 glucobrassicin은 모 든 광원에서 황 양액 농도가 증가할수록 함량이 증가하는 경향을 보였다(Fig. 2, Table 5). Progoitrin의 분해산물인 goitrin은 요오드의 흡수를 방해하고, 갑상선 호르몬인 티록신의 합성을 억제하는 갑상선종 유발물질로 알려져 있 고(Jahangir et al., 2009), glucobrassicin은 항암 효과가 뛰어난 indole-3-carbinol 의 전구체로 알려져 있다(Galletti et 



Fig. 2. Variations of progoitrin, glucobrassicin, sinigrin, and total glucosinolate (GSL) contents influenced by different concentrations of sulfur solution treatments in kale sprouts. $S$ solutions (mean, $n=12$ ) represent the average of total GSL contents with all light source treatments. These data were recalculated from Table 5.

Table 5. Average of glucosinolate contents ( $\mu \mathrm{mol} / \mathrm{g} \mathrm{DW})$ in kale sprouts.

\begin{tabular}{|c|c|c|c|c|c|c|c|c|c|}
\hline \multirow[b]{2}{*}{ No. ${ }^{x}$} & \multirow[b]{2}{*}{ Trivial name } & \multicolumn{4}{|c|}{$\mathrm{S}$ solutions $^{\mathrm{y}}(\mathrm{mM})($ mean, $n=12)$} & \multicolumn{4}{|c|}{ Light sources $^{\mathrm{z}}$ (mean, $n=12$ ) } \\
\hline & & S 0.0 & S 0.5 & 1.0 & S 2.0 & Fluo & Red LED & Blue LED & $\begin{array}{l}\text { Mix }(\mathrm{R}+\mathrm{B}) \\
\text { LED }\end{array}$ \\
\hline 1 & Progo & $3 \mathrm{a}$ & & & & & & & $3.45 \pm 0.72 \mathrm{a}$ \\
\hline 2 & Sinigrin & $142.54 \pm 12.02 \mathrm{a}$ & $144.55 \pm 7.18 \mathrm{a}$ & $137.03 \pm 11.43 \mathrm{a}$ & $133.73 \pm 13.74 a$ & $142.99 \pm 11.29 \mathrm{a}$ & $140.10 \pm 12.36 \mathrm{a}$ & $135.52 \pm 10.58 \mathrm{a}$ & $139.24 \pm 13.16 \mathrm{a}$ \\
\hline 3 & 4-Hydroxyglucobrassicin & $4.05 \pm 0.83 \mathrm{a}$ & $4.50 \pm 0.68 \mathrm{a}$ & $4.27 \pm 0.70 \mathrm{a}$ & $4.27 \pm 0.91 \mathrm{a}$ & $4.82 \pm 0.42 \mathrm{a}$ & $4.37 \pm 1.06 \mathrm{ab}$ & $4.07 \pm 0.70 \mathrm{ab}$ & $3.82 \pm 0.44 \mathrm{a}$ \\
\hline 4 & Glucobrassicin & $2.39 \pm 1.03 b$ & $4.09 \pm 1.95 \mathrm{ab}$ & $4.13 \pm 1.83 \mathrm{ab}$ & $6.11 \pm 3.02 \mathrm{a}$ & $2.60 \pm 0.64 b$ & $5.43 \pm 2.36 \mathrm{ab}$ & $2.44 \pm 1.04 b$ & $6.24 \pm 2.34 \mathrm{a}$ \\
\hline 5 & 4-Methoxyglucobrassicin & $1.45 \pm 0.39 \mathrm{a}$ & $1.49 \pm 0.30 \mathrm{a}$ & $1.29 \pm 0.16 \mathrm{a}$ & $1.52 \pm 0.21 \mathrm{a}$ & $1.57 \pm 0.13 \mathrm{a}$ & $1.44 \pm 0.31 \mathrm{ab}$ & $1.21 \pm 0.22 \mathrm{~b}$ & $1.53 \pm 0.34 a b$ \\
\hline 6 & Gluconasturtiin & $1.76+0.60 \mathrm{a}$ & $1.87 \pm 0.47 \mathrm{a}$ & $1.78 \pm 0.32 \mathrm{a}$ & $1.79 \pm 0.25 \mathrm{a}$ & $1.83 \pm 0.46 \mathrm{ab}$ & $2.22 \pm 0.33 \mathrm{a}$ & $1.51 \pm 0.28 b$ & $1.64 \pm 0.24 b$ \\
\hline \multirow[t]{2}{*}{7} & Neoglucobrassicin & $1.19 \pm 0.89 \mathrm{a}$ & $1.37 \pm 0.78 \mathrm{a}$ & $1.47 \pm 1.03 \mathrm{a}$ & $1.97 \pm 1.11 \mathrm{a}$ & $0.86 \pm 0.42 \mathrm{~b}$ & $2.33 \pm 0.89 \mathrm{a}$ & $0.54 \pm 0.30 \mathrm{~b}$ & $2.27 \pm 0.41 \mathrm{a}$ \\
\hline & Total & $156.93 \pm 13.22 \mathrm{a}$ & $160.97 \pm 9.04 a$ & $152.73 \pm 14.16 \mathrm{a}$ & $152.12 \pm 15.78 \mathrm{a}$ & $157.76 \pm 12.37 \mathrm{a}$ & $159.23 \pm 13.85 \mathrm{a}$ & $147.57 \pm 10.91 \mathrm{a}$ & $158.18 \pm 14.17 \mathrm{a}$ \\
\hline
\end{tabular}

${ }^{\mathrm{x}}$ No., the elution order of HPLC analysis (Fig. 1).

${ }^{\mathrm{y}} \mathrm{S}$ solutions (mean, $n=12$ ) represent the average of sum GSL contents with all light source treatments.

${ }^{z}$ Light sources (mean, $n=12$ ) represent the average of sum GSL contents with all S solutions treatments.

Within each column, values followed by the same letters are not significantly different at $\mathrm{p} \leq 0.05$, using Tukey's multiple-range test $(n=3)$.

al., 2006). Kestwal et al. (2011)은 glucobrassicin 함량이 브로콜리, 양배추, 무의 새싹 재배 시 황 $60 \mathrm{~kg} \cdot \mathrm{ha}^{-1}$ 처리 시 무처리구에 비해 $1.48,17.86,4.58$ 배 증가한다고 보고하였다. Schonhof et al. (2007)은 브로콜리 재배 시 충분한 양 의 질소 $\left(4.0 \mathrm{~g} \cdot \operatorname{pot}^{-1}\right)$ 와 많은 양의 황을 공급 $\left(1.0 \mathrm{~g} \cdot \operatorname{pot}^{-1}\right)$ 하여 재배한 식물에서 glucobrassicin이 포함된 indolyl $\mathrm{GSLs}$ 가 높은 농도 $\left(0.079 \mathrm{~g} \cdot \mathrm{kg}^{-1} \mathrm{FM}\right)$ 로 발견되었다고 보고하였으며, 이 식물이 충분하지 못한 $\mathrm{S}$ 를 공급 $(0.2 \mathrm{~g}$. $\mathrm{pot}^{-1}$ ) 받은 식물보다 indolyl GSLs 농도가 $70 \%$ 이상 높게 나타났다고 보고하였다. 그러나 본 실험에서 glucobrassicin 평균 함량은 황 양액 재배 시 기준 농도인 S $1.0 \mathrm{mM}$ 보다 S $0.5 \mathrm{mM}$ 이 형광등에서 1.09배, 적색 LED 에서 1.05 배, 청색 $\mathrm{LED}$ 에서 1.03 배, 적+청 혼합색 $\mathrm{LED}$ 에서 1.05 배 높게 나타났으며, 평균적으로 1.06 배 높게 나타 나 함량에 큰 변화가 나타나지 않았다(Table 5).

\section{형광등 및 LED 광원에 따른 GSL 함량}

광원에 따른 GSL 함량 범위는 147.57 (청색 LED) - 159.23 (적색 LED) 이었고, 각 GSL 성분별 함량 범위는 

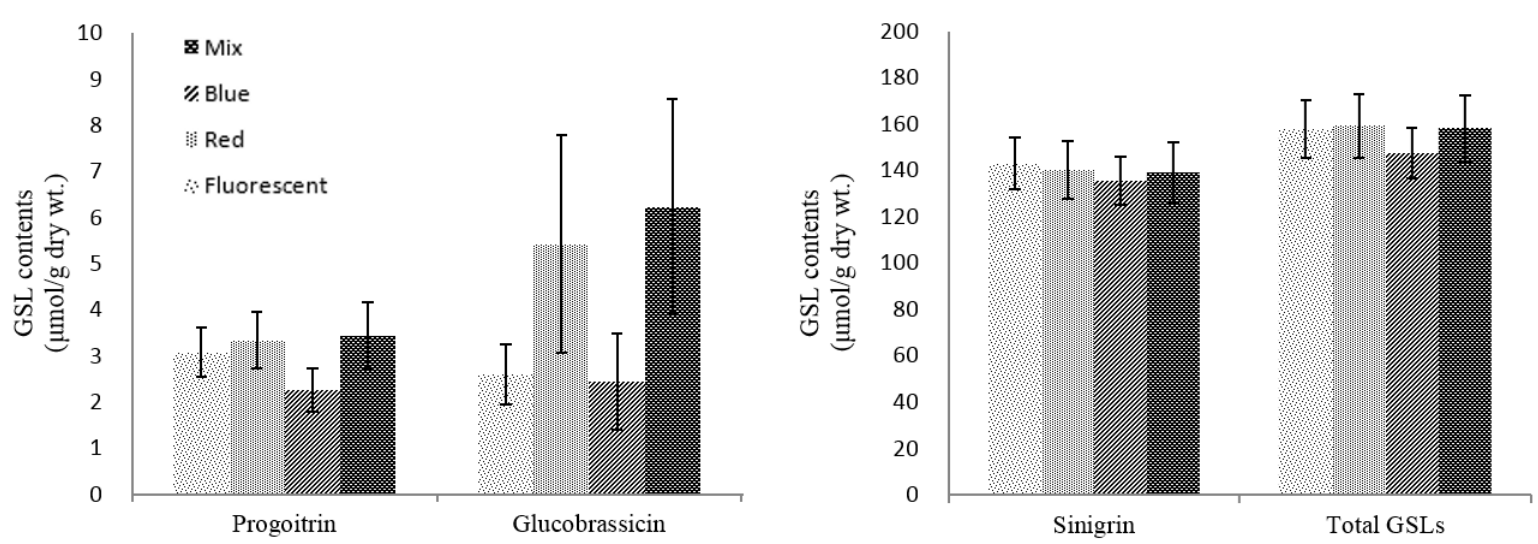

Fig. 3. Variations of progoitrin, glucobrassicin, sinigrin, and total glucosinolate (GSL) contents by different concentrations of sulfur solution treatments in kale sprouts. Light sources (mean, $n=12$ ) represent the average of total GSL contents with all $\mathrm{S}$ solutions treatments. These data were recalculated from Table 5.

progoitrin (2.26 - 3.45), sinigrin (135.52 - 142.99), 4-hydroxyglucobrassicin (3.82 - 4.82), glucobrassicin (2.44 - 6.24), 4-methoxyglucobrassicin (1.21 - 1.57), gluconasturtiin (1.51 - 2.22), neoglucobrassicin ( $\left.0.54-2.33 \mu \mathrm{mol} \cdot \mathrm{g}^{-1} \mathrm{DW}\right)$ 으 로 나타났다(Table 5). Carvalho and Folta (2014)는 케일 새싹 재배 시 모든 광원 처리구(백색, 근적외선, 적색, 청색 $\mathrm{LED})$ 에서 총 GSL 함량을 조사한 결과, 근적외선에서 가장 높게 나타났고(3.65), 다른 광원 처리구와 암조건을 비 교(2.57 - $3.12 \mu \mathrm{mol} \cdot \mathrm{g}^{-1} \mathrm{DW}$ )하면 약 15 - 42\% 더 높게 나타났다고 보고하였다. Lee et al. (2014a)에서 광원의 종류 에 따른 ‘신홍쌈’ 배추 내 총 GSL 함량을 조사한 결과, red + white (RW), red + blue + white (RBW), fluorescent lamp $(\mathrm{FL})$ 중 RW의 총 GSL 함량이 가장 낮고(26.51), RBW에서 재배한 배추 내 GSL 함량이 가장 높다고(28.98 $\mu \mathrm{mol}$. $\left.\mathrm{g}^{-1} \mathrm{DW}\right)$ 보고하였다. 그러나 본 실험에서는 청색 LED에서 재배한 케일 새싹채소의 총 GSL 함량이 가장 낮고 (147.57), 적색 $\mathrm{LED}$ 의 총 $\mathrm{GSL}$ 함량이 가장 높게 나타났다 $\left(159.23 \mu \mathrm{mol} \cdot \mathrm{g}^{-1} \mathrm{DW}\right)$. 형광등에서 각 $\mathrm{GSL}$ 성분별 평균 함량은 sinigrin (142.99) $>$ 4-hydroxyglucobrassicin (4.82) > progoitrin (3.08) > glucobrassicin $\left(2.60 \mu \mathrm{mol} \cdot \mathrm{g}^{-1} \mathrm{DW}\right)$, 적색, 청색, 적+청 혼합색 LED에서는 $\operatorname{sinigrin}(140.10,135.52,139.24)>4$-hydroxyglucobrassicin $(4.37,4.07,3.82)>$ glucobrassicin $(5.43,2.44,6.24)>$ progoitrin $\left(3.34,2.26,3.45 \mu \mathrm{mol} \cdot \mathrm{g}^{-1} \mathrm{DW}\right)$ 순으로 높았다(Table 5, Fig. 3). Carvalho and Folta (2014)에서 케일 새싹채소 내 indolyl GSLs 함량이 근적외선, 적색, 청색 빛에서 비슷한 함량을 나타냈으며 $(0.15,0.17,0.13)$, 백색 빛은 약 $40 \%$ 낮게 $\left(0.09 \mu \mathrm{mol} \cdot \mathrm{g}^{-1} \mathrm{DW}\right)$ 만들어 진다고 보고하였다. Indolyl GSLs 중 glucobrassicin은 암조건 $(0.18)$ 에서 보다 백색 $\left(0.06 \mu \mathrm{mol} \cdot \mathrm{g}^{-1} \mathrm{DW}\right)$ 에서 $67 \%$ 낮게 나타난 것을 확인할 수 있었다. 본 실험에서는 모든 $\mathrm{S}$ 양액 농도에서 glucobrassicin의 함량은 적색과 적+청 혼합색 $\mathrm{LED}$ 에서 높고, 형광등과 청색 LED에서 낮은 경향을 보였다. Carvalho and Folta (2014)의 연구결과에 의하면 케일 새싹채소를 재배할 때 aliphatic GSLs 중 glucoraphanin은 근적외선을 제외한 모든 조건에서 비슷한 함량을 나타냈으며, 암조건과 비교하 였을 때 약 $50 \%$ 가 증가했다고 보고되었다. 본 실험에서는 aliphatic GSLs 중 glucoraphanin이 분리 및 동정되지 않 았지만 aliphatic GSLs로 분류되는 progoitrin과 sinigrin의 함량 비율을 비교하였다. 총 GSL 함량 중 progoitrin 비율 은 청색 $\mathrm{LED}$ 에서 가장 낮게 나타났고, 형광등과 적색, 청색, 적+청 혼합색 $\mathrm{LED}$ 에서 총 $\mathrm{GSL}$ 함량 중 가장 높은 비 율을 나타낸 성분은 sinigrin으로 총 GSL 함량 중 93.5, 90.5, 94.4, 90.2\%를 차지하였다. Sinigrin (2-prophenyl GSL) 은 R이 allyl기인 glucosinolate로서 그 전구체는 homomethionine이다(Agerbirk and Olsen, 2012). Sinigrin의 분해산 물인 allyl isothiocyanate는 쥐에서 콜레스테롤 수치를 감소시키는 것으로 알려져 있고, 인간에게 종양 형성 저해와 간암, 폐암 위암과 같은 암 예방 효과가 있는 것으로 알려져 있다. 또 강한 항균, 살충작용과 같이 식물방어에 관여 하며, 선충류, 진균류, 여러 토양 미생물의 성장을 억제하는 효과가 있다(Zhang and Talalay, 1994; Velasco et al., 
2007; Cartea et al., 2008). Lee et al. (2014b)에서 케일 새싹채소와 동일 종의 성숙채소는 133 DAS (days after sowing)에서 sinigrin 함량이 총 GSL 함량 중 평균 $56.0 \%$ 로 나타났다. 따라서 새싹채소가 동일 종의 성숙채소보다 총 GSL 대비 sinigrin 함량이 높아 항암예방효과가 있을것으로 사료된다.

본 연구에서 광원은 총 GSL 함량에 영향을 미치지 않았으며 sinigrin 함량에도 영향을 미치지 않은 것으로 나타 났다(Table 6). Glucobrassicin은 형광등에서 황 0.5 와 1.0 를 제외한 황 양액 농도 사이에서 경향성이 나타났고, 적색 $\mathrm{LED}$ 에서 황 0.0 과 $2.0,0.5$ 와 2.0, 1.0 과 $2.0 \mathrm{mM}$ 사이에서 경향성이 나타났다. 청색 $\mathrm{LED}$ 에서 progoitrin은 황 0.0 과

Table 6. Statistical significance analysis of light sources and sulfur solutions and influences on progoitrin, sinigrin, glucobrassicin and total GSL contents in kale sprouts.

\begin{tabular}{|c|c|c|c|c|c|}
\hline \multirow{2}{*}{ Light source } & \multirow{2}{*}{ Treatment } & \multicolumn{4}{|c|}{ Individual GSLs } \\
\hline & & Progoitrin & Sinigrin & Glucobrassicin & Total GSLs \\
\hline Fluorescent & S $0.0 \times 0.5$ & $\mathrm{NS}^{\mathrm{y}}$ & NS & $*$ & NS \\
\hline \multirow[t]{5}{*}{$(n=3)$} & S $0.0 \times 1.0$ & NS & NS & $*$ & NS \\
\hline & S $0.0 \times 2.0$ & NS & NS & $*$ & NS \\
\hline & S $0.5 \times 1.0$ & NS & NS & NS & NS \\
\hline & S $0.5 \times 2.0$ & NS & NS & $*$ & NS \\
\hline & $\mathrm{S} 1.0 \times 2.0$ & NS & NS & $*$ & NS \\
\hline Red LED & S $0.0 \times 0.5$ & NS & NS & NS & NS \\
\hline \multirow[t]{5}{*}{$(n=3)$} & S $0.0 \times 1.0$ & NS & NS & NS & NS \\
\hline & S $0.0 \times 2.0$ & NS & NS & * & NS \\
\hline & S $0.5 \times 1.0$ & NS & NS & NS & NS \\
\hline & S $0.5 \times 2.0$ & NS & NS & $*$ & NS \\
\hline & $\mathrm{S} 1.0 \times 2.0$ & NS & NS & $*$ & NS \\
\hline Blue LED & S $0.0 \times 0.5$ & NS & NS & NS & NS \\
\hline \multirow[t]{5}{*}{$(n=3)$} & $\mathrm{S} 0.0 \times 1.0$ & * & NS & NS & NS \\
\hline & S $0.0 \times 2.0$ & $*$ & NS & $*$ & NS \\
\hline & $\mathrm{S} 0.5 \times 1.0$ & NS & NS & NS & NS \\
\hline & S $0.5 \times 2.0$ & NS & NS & NS & NS \\
\hline & $\mathrm{S} 1.0 \times 2.0$ & NS & NS & $*$ & NS \\
\hline Mix $(\mathrm{R}+\mathrm{B}) \mathrm{LED}$ & S $0.0 \times 0.5$ & NS & NS & NS & NS \\
\hline \multirow[t]{5}{*}{$(n=3)$} & S $0.0 \times 1.0$ & NS & NS & NS & NS \\
\hline & $\mathrm{S} 0.0 \times 2.0$ & * & NS & * & NS \\
\hline & S0.5 $\times 1.0$ & NS & NS & NS & NS \\
\hline & S $0.5 \times 2.0$ & NS & NS & NS & NS \\
\hline & $\mathrm{S} 1.0 \times 2.0$ & NS & NS & NS & NS \\
\hline Mean $^{2}$ & S $0.0 \times 0.5$ & NS & NS & NS & NS \\
\hline \multirow[t]{5}{*}{$(n=12)$} & S $0.0 \times 1.0$ & $*$ & NS & NS & NS \\
\hline & S $0.0 \times 2.0$ & $*$ & NS & $*$ & NS \\
\hline & S $0.5 \times 1.0$ & NS & NS & NS & NS \\
\hline & S $0.5 \times 2.0$ & NS & NS & NS & NS \\
\hline & $\mathrm{S} 1.0 \times 2.0$ & NS & NS & NS & NS \\
\hline Mean $(n=48)$ & Light $\times$ Sulfur & NS & NS & NS & NS \\
\hline
\end{tabular}

${ }^{\mathrm{y}} \mathrm{NS}$, not significant.

${ }^{z}$ Mean, sum of GSL content in same sulfur treatment under all light sources. These were copied static data from Table 3 and 4.

*The data were analyzed using ANOVA with the means of three replicates $(p \leq 0.05)$. 
$1.0,0.0$ 과 2.0 사이에서 경향성이 나타났고, glucobrassicin은 황 0.0 과 $2.0,1.0$ 과 $2.0 \mathrm{mM}$ 사이에서 경향성이 나타났 다. 적+청 혼합색 LED에서 progoitrin, glucobrassicin은 황 0.0 과 황 $2.0 \mathrm{mM}$ 사이에서 경향성이 나타났다. 황 양액 농도는 총 GSL 함량과 sinigrin 함량에도 영향을 미치지 않았다. Progoitrin은 황 0.0 과 $1.0,0.0$ 과 2.0 사이에서 경 향성이 나타났고, glucobrassicin은 황 0.0 과 황 $2.0 \mathrm{mM}$ 사이에서 경향성이 나타났다. 따라서 각 광원에서 황 양액 농도 간 progoitrin, glucobrassicin은 상관관계가 있었으며, 광원과 황 양액 농도의 관계는 progoitrin, sinigrin, glucobrassicin, total GSLs에서 통계적 유의성이 나타나지 않았다.

\section{Acknowledgements}

이 연구는 충남대학교 공무국외여행(파견)의 지원을 받아 수행되었음.

\section{References}

Agerbirk N, Olsen CE. 2012. Glucosinolate structures in evolution. Phytochemistry 77:16-45.

Bula RJ, Morrow RC, Tibbitts TW, Barta DJ, Ignatius RW, Martin TS. 1991. Light-emitting diodes as a radiation sources for plants. HortScience 26:203-205.

Cartea ME, Velasco P, Obregón S, Padilla G, de Haro A. 2008. Seasonal variation in glucosinolate content in Brassica oleracea crops grown in northwestern Spain. Phytochemistry 69:403-410.

Carvalho SD, Folta KM. 2014. Sequential light programs shape kale (Brassica napus) sprout appearance and alter metabolic and nutrient content. Horticulture Research 8:1-13.

Choi YH, Park KY, Lee SM, Yoo MA, Lee WH. 1995. Inhibitory effect of the fresh juice of kale on the genotoxicity of aflatoxin B1. Korean Journal of Genetics 17:183-190. [in Korean]

Clarke DB. 2010. Glucosinolates, structures and analysis in food. Analytical Methods 2:310-325.

Fahey JW, Zalcmann AT, Talalay P. 2001. The chemical diversity and distribution of glucosinolates and isothiocyanates among plants. Phytochemistry 56:5-51.

Falk KL, Tokuhisa JG, Gershenzon J. 2007. The effect of sulfur nutrition on plant glucosinolate content: Physiology and molecular mechanisms. Plant Biology 9:573-581.

Galletti S, Barillari J, lori R, Venturi G. 2006. Glucobrassicin enhancement in woad (Isatis tinctoria) leaves by chemical and physical treatments. Journal of the Science of Food and Agriculture 86:1833-1838.

Goins GD, Yorio NC, Sanwo MM, Brown CS. 1997. Photomorphogenesis, photosynthesis, and seed yield of wheat plants grown under red light-emitting diodes (LEDs) with and without supplemental blue lighting. Journal of Experimental Botany 48:1407-1413.

Halkier BA, Du L. 1997. The biosynthesis of glucosinolates. Trends in Plant Science 2:425-431.

Hayes JD, Kelleher MO, Eggleston IM. 2007. Anticarcinogenic effects of glucosinolate breakdown products. Dietary vitamins, polyphenols, selenium and probiotics: Biomarkers of exposure and mechanisms of anticarcinogenic action. pp. 140-159. Nofer Institute of Occupational Medicine. Lodz, Poland.

Heo JW, Kim DE, Han KS, Kim SJ. 2013. Effect of light-quality control on growth of Ledebouriella seseloides grown in plant factory of an artificial light type. Korean Journal of Environmental Agriculture 32:193-200. [in Korean]

Hirai MY, Fujiwara T, Awazuhara M, Kimura T, Noji M, Saito K. 2003. Global expression profiling of sulfur-starved Arabidopsis by DNA macro array reveals the role of O-acetyl-L-serine as a general regulator of gene expression in response to sulfur nutrition. The Plant Journal 33:651-663.

International Standards Organization (ISO). 1992. Rapeseed: Determination of glucosinolates content -Part 1: 
Method using high performance liquid chromatography. pp. 1-9. ISO 9167-1 (E). Geneva, Switzerland. Jahangir M, Kim HK, Choi YH, Verpoorte R. 2009. Health-affecting compounds in Brassicaceae. Comprehensive Reviews in Food Science and Food Safety 8:31-43.

Kang HM, Kim IS, Won JH. 2005. Evaluation of internal quality of kale leaf by non-destructive color measurement. Journal of Bio-Environment Control 14:144-148. [in Korean]

Kestwal RM, Lin JC, Kestwal DB, Chiang BH. 2011. Glucosinolates fortification of cruciferous sprouts by sulphur supplementation during cultivation to enhance anti-cancer activity. Food Chemistry 126:1164-1171.

Kim KH, Kim HJ, Byun MW, Yook HS. 2012. Antioxidant and antimicrobial activities of ethanol extract from six vegetables containing different sulfur compounds. Journal of the Korean Society of Food Science and Nutrition 41:577-583. [in Korean]

Lee GR, Kim YJ, Chun JH, Lee MK, Ryu DK, Park SH, Chung SO, Park SU, Lim YP, Kim SJ. 2014a. Variation of glucosinolate contents of 'Sinhongssam' grown under various light sources, periods, and light intensities. CNU Journal of Agricultural Science 41:125-133. [in Korean]

Lee HH, Yang SC, Lee MK, Ryu DK, Park SH, Chung SO, Park SU, Lim YP, Kim SJ 2014b. Effect of developmental stages on glucosinolate contents in kale (Brassica oleraceavar. acephala). Korean Journal of Horticultural Science \& Technology 33:177-185. [in Korean]

Lee MJ, Lim SY, Kim JK, OH MM. 2012. Heat shock treatments induce the accumulation of phytochemicals in kale sprouts. Korean Journal of Horticultural Science \& Technology 30:509-518. [in Korean]

Lefsrud MG, Kopsell DA, Sams CE, 2008. Irradiance from distinct wavelength light-emitting diodes affect secondary metabolites in kale. HortScience 43:2243-2244.

Maruyama-Nakashita A, Inoue E, Watanabe-Takahashi A, Yamaya T, Takahashi H. 2003. Transcriptome profiling of sulfur-responsive genes in Arabidopsis reveals global effects of sulfur nutrition on multiple metabolic pathways. Plant Physiology 132:1-9.

Massa GD, Kim HH, Wheeler RM, Mitchell CA. 2008. Plant productivity in response to LED lighting. HortScience 43:1951-1956.

Matsuda RK, Ohashi-Kaneko K, Fujiwara K, Goto E, Kurata K. 2004. Photosynthetic characteristics of rice leaves grown under red light with or without supplemental blue light. Plant and Cell Physiology 45:1870-1874.

Rosa E, Heaney R. 1996. Seasonal variation in protein, mineral and glucosinolate composition of Portuguese cabbages and kale. Animal Feed Science Technology 57:111-127.

Schonhof I, Blankendurg D, Muller S, Krumbein A. 2007. Sulfur and nitrogen supply influence growth, product appearance, and glucosinolate concenetation of broccoli. Journal of Plant Nutrition and Soil Science 170:1-8.

Schwartz A, Zeiger E. 1984. Metabolic energy for stomatal opening: Roles of photophosphorylation and oxidative phosphorylation. Planta 161:129-136.

Velasco P, Cartea ME, Gonzaa LC, Vilar M, Ordaa SA. 2007. Factors affecting the glucosinolate content of kale (Brassica oleracea acephala group). Journal of Agricultural and Food Chemistry 55:955-962.

Yorio NC, Goins GD, Kagie HR. 2001. Improving spinach, radish, and lettuce growth under red light-emitting diodes (LEDs) with blue light supplementation. HortScience 36:380-383.

Zhang Y, Talalay P. 1994. Anticarcinogenic activities of organic isothiocyanates: Chemistry and mechanisms. Cancer Research 54:1976-1981. 